Original Research

\title{
A Comparative Study of Structural, Optical and Electrical Properties of Fe- ZnO Nanoparticles Synthesized by Precipitation and Microwave Method for Photovoltaic Applications
}

Ganga R. Neupane ${ }^{1}$, Amrit Kaphle ${ }^{1}$, David N. Mcllroy ${ }^{2,3}$, Elena Echeverria ${ }^{2}$, Prasanna Sankaran ${ }^{2,}$, Parameswar Hari ${ }^{1,3, *}$

1. Department of Physics and Engineering Physics, University of Tulsa, Tulsa, Oklahoma 74104, USA; E-Mails: ganga-neupane@utulsa.edu; Amrit-kaphle@utulsa.edu; hari@utulsa.edu

2. Department of Physics, Oklahoma State University, Stillwater, Oklahoma 74078, USA; E-Mails: david.mcilroy@okstate.edu; elena.echeverria@okstate.edu; prasli79@gmail.com

3. Oklahoma Photovoltaic Research Institute, University of Tulsa, Tulsa, Oklahoma 74104, USA

¥ Current Affiliation: Department of Physics, PSG College of Technology, Coimbatore - 641004 , TamilNadu, India

* Correspondence: Parameswar Hari; E-Mail: hari@utulsa.edu

Academic Editor: Kwok Wei Shah

Special Issue: Nanostructured Materials for Clean \& Sustainable Energy Storage \& Efficiency for Wellness \& Green Buildings

Journal of Energy and Power Technology

2021, volume 3, issue 3

doi:10.21926/jept.2103035
Received: May 12, 2021

Accepted: July 15, 2021

Published: August 04, 2021

\begin{abstract}
Iron doped $\mathrm{ZnO}$ (Fe-ZnO) nanoparticles were synthesized using two techniques that are economical as well as scalable to yield tunable properties of nanoparticles for facilitating down conversion in an absorbing layer of a solar cell. To evaluate the suitability of Fe-ZnO nanoparticles prepared by two deposition methods, we present a comparison of optical, electrical, and structural properties of Fe-ZnO using several experimental techniques. Structural properties were analyzed using transmission electron microscopy and $\mathrm{x}$-ray diffraction spectroscopy (XRD) with Rietveld analysis for extracting information on
\end{abstract}

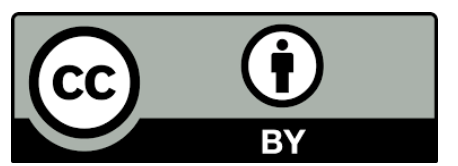

(c) 2021 by the author. This is an open access article distributed under the conditions of the Creative Commons by Attribution License, which permits unrestricted use, distribution, and reproduction in any medium or format, provided the original work is correctly cited. 
compositional variations with Fe doping. The chemical composition of nanoparticles was analyzed through X-ray photoelectron spectroscopy (XPS). The optical properties of nanoparticles were studied using photoluminescence and UV-Vis absorption spectroscopy. In addition, fluorescence lifetime measurement was also performed to study the changes in an exponential decay of lifetimes. The electrical transport properties of Fe-ZnO were analyzed by impedance spectroscopy. Our studies indicate that ethanol as a solvent in a microwave method would produce smaller nanoparticles up to the size of $11 \mathrm{~nm}$. In contrast, the precipitation method produces secondary phases of $\mathrm{Fe}_{2} \mathrm{O}_{3}$ beyond $5 \%$ doping. In addition, our studies show that the optical and electrical properties of resulting Fe-ZnO nanoparticles depend on the particle sizes and the synthesis techniques used. These new results provide insight into the role of solvents in fabricating Fe-ZnO nanoparticles by precipitation and microwave methods for photovoltaic and other applications.

\section{Keywords}

ZnO nanoparticles; precipitation, microwave method; rietveld analysis; X-ray photoelectron spectroscopy; fluorescent lifetime; impedance measurement; nyquist plot

\section{Introduction}

ZnO nanomaterials have attracted a great deal of attention in the scientific community due to their range of structural, electrical, and optical properties. Material design and fabrication, including synthesis, characterization, and device application of nanostructures, are actively studied by various groups. Exploring various synthesis methods of nanomaterials is crucial for tailoring the optical, structural, and electrical properties of nanomaterials. $\mathrm{ZnO}$, an n-type semiconductor has a wide bandgap energy $\left(E_{g}=3.37 \mathrm{eV}\right)$ and a large exciton binding energy of $60 \mathrm{meV}$. Recently, ZnO nanoparticles have received significant attention due to the wide range of morphologies they exhibit and potential applications to spintronics [1]. In recent years, transition metal-doped ZnO has been extensively investigated because of its chemical, mechanical, electrical, optical, and magnetic properties [2, 3]. A wide range of techniques has been used to synthesize ZnO, such as sol-gel [4], laser-assisted chemical vapor deposition [5], solvothermal [6], hydrothermal [7], and microwaveassisted method [8]. Among these techniques, the hydrothermal-precipitation method and microwave methods are of great interest because of cost-effectiveness, safety considerations, and rapid deposition of nanoparticles. These techniques, solution-based techniques, in particular, have gained significant interest because they offer several advantages over other deposition techniques, such as low processing temperature, the maximum tunability in controlling the size and morphology of the resulting nanostructures.

Nanoparticles are unique physical and chemical systems because their relatively large surface area influences the physical, chemical, and structural properties. In addition, the Optical and electrical properties of nanoparticles are also size-dependent. Because of these unique characteristics, they are suitable candidates for various applications such as catalysis, bio-imaging material, medical applications, energy-based research, and environmental applications [9]. There are many examples from the literature illustrating the applications of synthesizing nanoparticles in 
these areas. For example, Subban et al. [10] synthesized $\mathrm{TiWO}_{2}$ nanoparticles and used them as catalysis. They found from an electrochemical test that the rates of hydrogen oxidation and oxygen reduction by platinum nanoparticles supported on $\mathrm{TiWO}_{2}$ are comparable to those of commercial Pt on carbon black. Nanoparticles such as dye-doped silica nanoparticles and gold nanoparticles are now being developed for absorbance and emission in the near-infrared region, which is expected to allow for real-time and deep tissue imaging via optical routes [11]. Nanoparticles are also developed for potential applications in cancer treatment. Magnetic nanoparticles such as Fe-ZnO provide novel ways to deliver cancer drugs to a specific site without disturbing the surrounding areas. These particles allow exquisite modification for binding to cancer cell membranes or nuclear receptor sites. Delivery of high drug concentrations to the targeted cancer cells [12] has been already demonstrated. Nanoparticles have also been used for electrochemical energy storage. It was found that for nanoparticles below $10 \mathrm{~nm}$, capacitive contributions became increasingly important, leading to greater amounts of total stored charge [13]. Nanoparticles can also be used in the detection and monitoring of microorganisms in fluorescence labeling systems in microfluidic devices. They can also be further conjugated with specific antibodies to detect pathogenic microorganisms such as Cryptosporidium parvum and Giardia lambli [14]. Fe and Co-doped ZnO nanoparticles are also promising candidates for semiconductor-based spintronic devices [15]. Omri et al. [16] studied the optoelectronic properties of Cu-doped ZnO nanoparticles. They found that the current conductivity increases with increasing $\mathrm{Cu}$ content despite a decrease in activation energy. Jun et al. [17] also studied ultraviolet photodetectors based on $\mathrm{ZnO}$ nanoparticles. They found the ratio of photocurrent to the dark current was as high as $10^{6}$, which is favorable for application as a photodetector. Similarly, Singh et al. [18] studied structure, photophysics, and optoelectronics application of modified $\mathrm{ZnO}$ nanoparticles. The modified $\mathrm{ZnO}$ was incorporated in light-emitting diodes and the device performance was explored. Several researchers have studied the room temperature ferromagnetism in Fe and Co-doped $\mathrm{ZnO}$ nanomaterials. Mohapatra et al. [19] found the room temperature ferromagnetism in Co-doped $\mathrm{ZnO}$ within an optimal doping level of $5 \%$. Wu et al. [20] also found the room temperature ferromagnetism in Fe doped ZnO nanoparticles by hydrothermal synthesis. Similarly, Gu et al. [21] reported defect-induced room temperature ferromagnetism in Fe and $\mathrm{Na}$ co-doped $\mathrm{ZnO}$ nanoparticles. This behavior was attributed to the exchange via electron trapped oxygen vacancies coupled with magnetic Fe ions. High conductivity can be achieved by doping with a transition metal, which in turn leads to the application of surface acoustic wave devices and transparent conducting electrodes.

It is well known that the size of nanoparticles strongly influences the properties of the nanofilm made from the nanoparticles. As we already know that photovoltaic cells based on silicon have reached efficiencies of up to $25 \%$, which is close to the limit of about $33 \%$ predicted by Shockley and Queisser [22]. The practical limitation also arises from the non-radiative recombination processes at the front and back surface of the solar cell. Here considering the limitations based on the analysis of Shockley and Queisser, it appears attractive to modify the spectrum of sunlight by down conversion before it enters the solar cell. This can be done by synthesizing suitable nanoparticles of various sizes which can down-convert the photons by generating multiple photons out of one absorbed photon.

However, the most crucial challenge in the fabrication process is the design of a synthesis method that can yield tunable nanoparticles in a very short time based on a simple and cost-effective deposition technique. Synthesis of nanoparticles is often accomplished by sputtering, chemical 
vapor deposition, and sol-gel techniques [23-25]. These techniques require sophisticated systems which are costly and consume lots of energy and time. In comparison with other conventional methods, synthesis by microwave method has the advantage of having a short time of reaction due to the combined forces created by both electric and magnetic components of microwave irradiation. There are several reports on the fabrication of transitional metal-doped $\mathrm{ZnO}$ nanoparticles [26] by conventional techniques and microwave-assisted methods. K. Hossienzadeh et al. [27] synthesized undoped, Ag-, Cu-, Mg- and Ce-doped $\mathrm{ZnO}$ nanoparticles using the solvothermal method. S. Aiswarya et al. [28] synthesized undoped and Fe-doped $\mathrm{ZnO}$ nanoparticles using Amaranthus spinosus leaf extract as a reducing agent. Limaye et al. [29] used the microwave-assisted synthesis method to synthesize Fe-doped ZnO nanorods instead of nanoparticles. Glaspell et al. [30] synthesized Co-, Cr-, Fe-, Mn-, and Ni-doped ZnO using microwave method operated in 30 seconds cycles for $10 \mathrm{~min}$. To our best knowledge, there are no reported studies on synthesizing Fe-ZnO nanoparticles using a microwave with two different solvents (deionized water and ethanol) below 5 min of irradiation.

The main objective of this study is to fabricate Fe doped $\mathrm{ZnO}$ nanoparticles using hydrothermal precipitation and microwave method and to investigate the differences in structural, electrical, and optical properties of Fe-ZnO prepared by these two methods. Up to our knowledge, there is no comparative study on Fe-ZnO nanoparticles using simple hydrothermal and microwave methods with two different solvents. This study will guide to fabrication of Fe-ZnO nanoparticles with tunable size for photovoltaic application. One important variable in this study is the choice of solvent used in a deposition. To study the effect of solvent in controlling the particle size under these deposition methods, we used water and ethyl alcohol as solvents. The precipitation method is limited to using water as a solvent, whereas the microwave method uses both deionized water and ethyl alcohol as solvents. Using these deposition techniques and two different solvents, we synthesized a range of Fe-doped $\mathrm{ZnO}$ nanoparticles with different Fe content and compared the structural, optical, and electrical properties of the resulting nanoparticles.

\section{Materials and Methods}

\subsection{Materials}

The chemicals, zinc acetate dihydrate $\left[\mathrm{Zn}\left(\mathrm{CH}_{3} \mathrm{COO}\right)_{2} .2 \mathrm{H}_{2} \mathrm{O},>99.5 \%\right]$, iron nitrate nonahydrate [Fe( $\left.\mathrm{NO})_{3} .9 \mathrm{H}_{2} \mathrm{O},>98 \%\right]$, sodium hydroxide $[\mathrm{NaOH},>97 \%]$, polyvinylpyrrolidone (PVP) $\left[\left(\mathrm{C}_{6} \mathrm{H}_{9} \mathrm{NO}\right)_{n}\right]$, ethyl alcohol $\left[\mathrm{C}_{2} \mathrm{H}_{6} \mathrm{O},>98 \%\right]$ and acetone $\left[\mathrm{C}_{3} \mathrm{H}_{6} \mathrm{O},>99.5 \%\right]$ were purchased from Sigma Aldrich and were all used without further purification.

\subsection{Methods}

ZnO nanoparticles were synthesized by both precipitation and microwave method using deionized water as a solvent with zinc acetate dihydrate and sodium hydroxide as a precursor. In this experiment, zinc acetate dehydrate was mixed with deionized water. The solution was stirred continuously with a magnetic stirrer, and sodium hydroxide was added to make the $\mathrm{pH}$ of the solution to be 11 . To synthesize nanoparticles from the microwave, the obtained final solution was kept at Hamilton Beach microwave with steel reinforced chassis (Model No. EM720CGA-PMB) at $140 \mathrm{~W}$ for 5 minutes. In the precipitation method, the solution was heated at $70{ }^{\circ} \mathrm{C}$ for two hours 
with continuous stirring. For the variation in the percentage of Fe-doping in both methods, different weight percentage $(5 \%, 10 \%$, and $15 \%)$ of iron nitrate was used. The solution was centrifuged and washed several times with acetone and deionized water. The precipitates were calcinated at $100{ }^{\circ} \mathrm{C}$ for an hour. Using ethanol as a solvent, the final solution was heated in the same microwave at 210W for 2 minutes. Finally, the powder was crushed, samples were prepared as ZnO nanoparticles for characterization. For tracking the two sets of samples prepared by deionized water and ethanol, we categorized samples prepared in the microwave using deionized water as microwave $A$ and samples prepared with ethanol in the same microwave as microwave B.

Samples were characterized using the following instruments. Hitachi $\mathrm{H} 700 \mathrm{O}$ was used to collect TEM images at 75kV. A Rigaku SmartLab diffractometer with CuK $\alpha_{1}$ radiation, $\lambda=1.54 \mathrm{~A}^{0}$ operated at $40 \mathrm{kV}$ and $44 \mathrm{~mA}$ was employed for measuring the XRD spectra. The PL and the UV-vis spectra were recorded using a Spectrofluorometer (Jasco, FP-6500) and a Varian Carry 50 Scan UV spectrophotometer, respectively. Fluorescent lifetime was measured using Life Spec II (Edinburgh Instruments, EPLED-610). XPS was performed in an ultra-high vacuum (UHV) system with a base pressure of $6.0 \times 10^{-10}$ Torr. XPS spectra were acquired using the Al-k $\alpha$ emission life from a dual anode $x$-ray source (Physical Electronics XR 04-548) operated at $400 \mathrm{~W}$ and an incident angle of $54.7^{\circ}$. The kinetic energy of the photoelectrons was collected and analyzed with an Omicron EA 125 hemispherical electron energy analyzer with a resolution of $0.02 \mathrm{eV}$. Impedance spectra were measured using Bode 100 with 10-24 VDC/10 W.

\section{Results and Discussion}

\subsection{Morphological Studies}

The microstructure and morphology of all samples were studied by transmission electron microscopy (TEM). Figure 1(a, b, c) shows TEM images of ZnO nanoparticles synthesized by both precipitation and the microwave method. Commercially available Image J software was used to process TEM images. From the TEM analysis, as shown in Figure $1(\mathrm{~d})$, it was observed that the average diameter of particles (calculated by averaging 25-30 nanoparticles in each cluster) obtained from the precipitation method decreases from $87 \mathrm{~nm}$ to $55 \mathrm{~nm}$ whereas the diameter decreases from $17 \mathrm{~nm}$ to $11 \mathrm{~nm}$ when prepared by microwave method $B$ as the iron concentration increased from $0 \%$ to $15 \%$. A similar result was also observed in a precipitation study of Fe-ZnO at low concentration by Yu et al. [31]. They reported a decrease in particle size from $100 \mathrm{~nm}$ to $80 \mathrm{~nm}$ when the iron concentration increased from 1 to $3 \%$. 


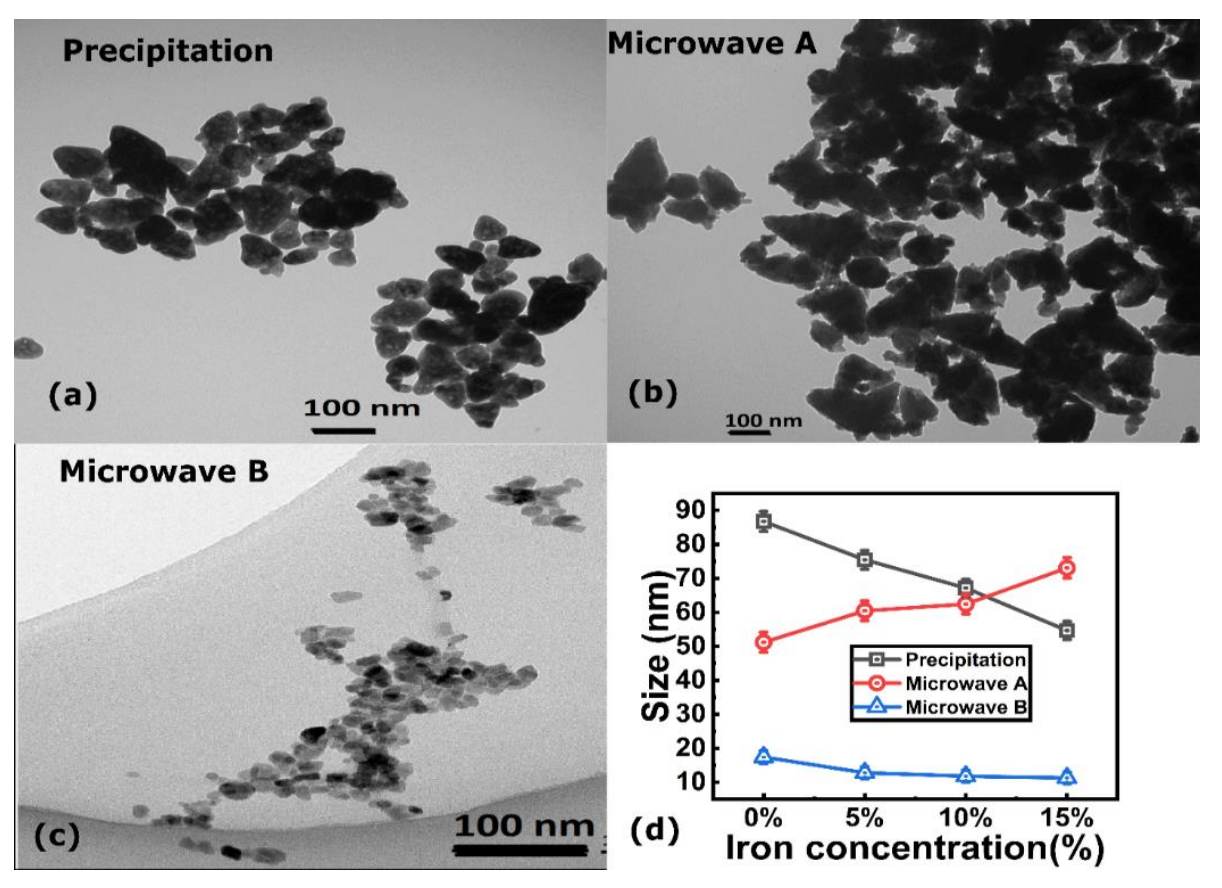

Figure 1 TEM images of ZnO nanoparticles prepared by (a) precipitation method, (b,c) microwave method, and (d) variation in size of Fe-ZnO nanoparticles with different iron concentrations.

The average diameter of particles increases from $51 \mathrm{~nm}$ to $74 \mathrm{~nm}$ as prepared by microwave method $A$ (where water was used as the solvent), which is shown in Figure 1 (d) as a function of iron concentration from 0 to $15 \%$. In contrast, nanoparticles prepared by microwave method B (using ethanol as the solvent) yielded smaller particle sizes. Fe-ZnO nanoparticles showed a decrease in size with Fe concentration (Figure 1 (d)) when ethanol was used as a solvent in a microwave deposition. This effect could be attributed to solid-state diffusion [32], which is responsible for the transport of atoms or ions of solid reactants and product during the reaction and crystal growth of the solid product. Singh [33] synthesized nanoparticles using the microwave method and calculated particle size using the effective mass approximation method, which was in good agreement with the result obtained from scanning electron microscopy (SEM) and observed a similar increase in particle size when $\mathrm{ZnO}$ was doped with manganese $(\mathrm{Mn})$. The average particle size for pure (undoped) $\mathrm{ZnO}$ in this study was found to be in the range 10-60 nm while size increased in the range 50-100 $\mathrm{nm}$ when doped with Mn using the microwave method.

The decrease in particle size from 17-11 nm was observed when ethanol was used instead of deionized water in the microwave synthesis method. This may be due to the lower dielectric constant of alcohol compared to water. As the dielectric constant becomes small, the ability of the material will significantly increase to absorb microwaves and convert them into heat [34], which results in smaller nanoparticles. In addition, in their studies, PVP (polyvinylpyrrolidone) was used as a capping reagent, which reduces the strong interaction between the surfaces of nanocrystals that is believed to be a deterrent to solid-state diffusion. The decrease in particle size with an increase in iron concentration was also observed by Fabbiyola et al. [35]. These studies indicate that with increasing iron concentration, $\mathrm{Fe}^{3+}$ ions inhibit the nucleation and growth of nanocrystals. These reported trends of both increase and decrease in particle size with Fe content may be due to different preparation conditions and different solvents used in fabrication methods. 


\subsection{X-ray Diffraction (XRD) Analysis}

Figure 2(a) and Figure 3(a, c) show XRD patterns of pure $\mathrm{ZnO}, 5 \%, 10 \%$, and $15 \%$ iron-doped $\mathrm{ZnO}$ nanoparticles prepared by the precipitation method and microwave method. All XRD peaks can be matched and indexed to the hexagonal phase $\mathrm{ZnO}$ of the wurtzite structure according to standard JCPDS card no.36-1451 [36]. Moreover, no secondary phases and impurity within the detection limit of XRD were observed, and no visible diffraction patterns of $\mathrm{Fe}$ species such as $\mathrm{Fe}, \mathrm{Fe}_{2} \mathrm{O}_{3}$, and $\mathrm{Fe}_{3} \mathrm{O}_{4}$ have been detected for $\mathrm{ZnO}$ samples doped with Fe below $10 \%$. This result may be an indication that the Fe atom has successfully been incorporated in $\mathrm{ZnO}$ lattice preserving the wurtzite structure of $\mathrm{ZnO}$ except for the higher concentration of $\mathrm{Fe}-\mathrm{ZnO}$ with $\mathrm{Fe}$ at $10 \%$ and $15 \%$ prepared by precipitation method.
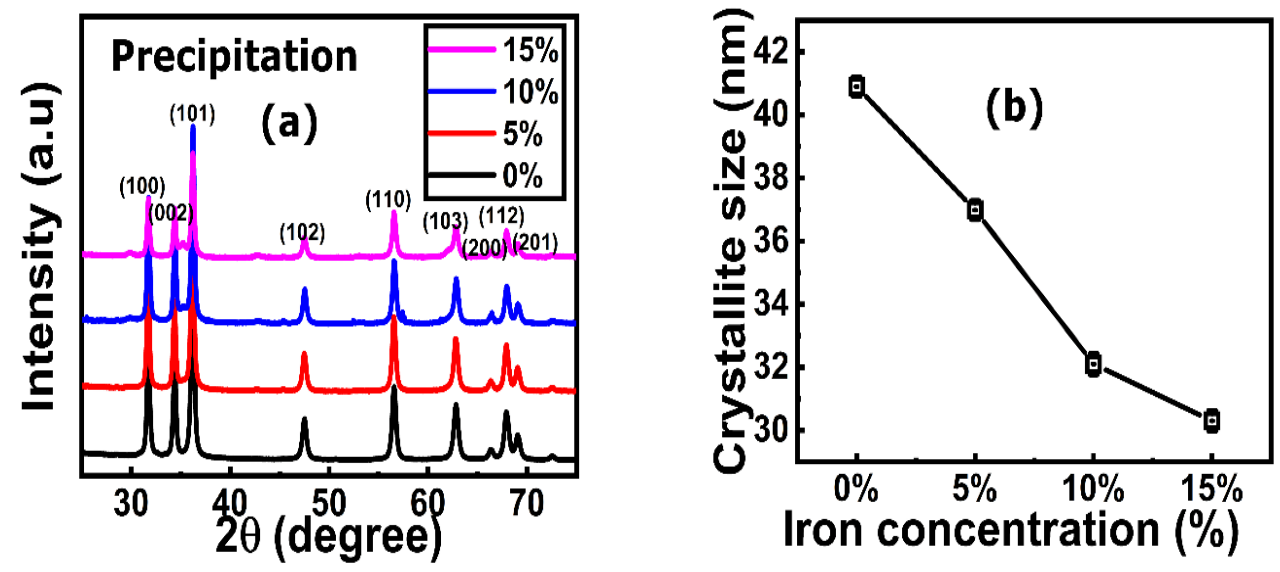

Figure 2 X-ray diffraction spectra (a) and crystallite size of Fe-ZnO nanoparticles (b) prepared by precipitation method.
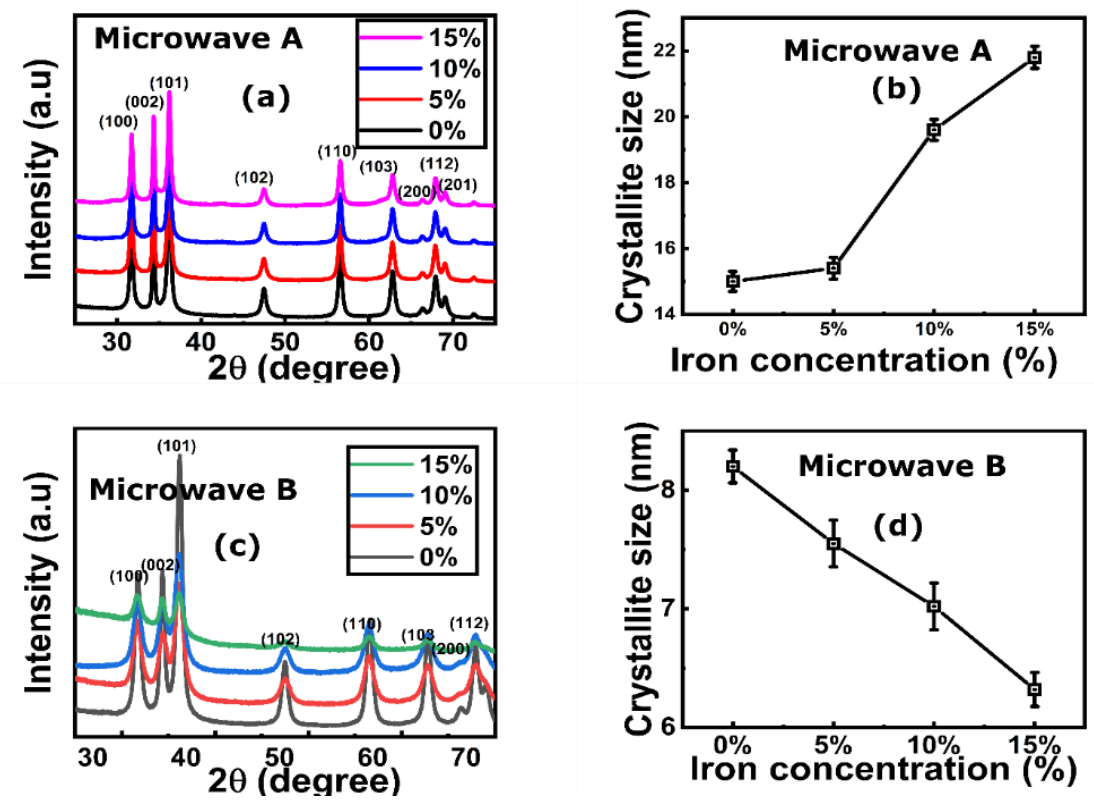

Figure $3(a, c)$ X-ray diffraction spectra and (b, d) crystallite size of Fe-ZnO nanoparticles prepared by the microwave method. 


\subsection{Rietveld Analysis of XRD Data on Fe-ZnO}

Rietveld refinement analysis was performed to characterize the structural aspect of prepared nanoparticles using the PDXL software program [37-39]. Figure 4 shows the observed and calculated patterns in the same field as solid line curves, black and red respectively. The vertical olive lines mark the angular positions of the $\mathrm{ZnO}$ reflections. The difference between observed and calculated lines is shown in the lower field in blue. The pie chart represents the number of phases in samples obtained from the Rietveld analysis. From the XRD Rietveld analysis, the hexagonal wurtzite structure was confirmed for all prepared nanoparticles. However, small peaks corresponding to cubic $\mathrm{ZnFe}_{2} \mathrm{O}_{3}$ were observed in the XRD patterns of $10 \%$ and $15 \%$ Fe-doped $\mathrm{ZnO}$ nanoparticles prepared by the precipitation method. The formation of a secondary phase in zinc iron oxide structure- for nanoparticles above 5\% Fe doping is due to the coexistence of $\mathrm{Fe}^{3+}$ and $\mathrm{Fe}^{2+}$ ions in our samples [40]. The obtained values of fit parameters from the analysis are in Table 1, Table 2, and Table 3. The goodness of fit $(S)$ is calculated from $S=R_{w p} / R_{e}$, where $R_{w p}$ and $R_{e}$ are the weighted profile and expected weighted profile reliability factors, respectively. All $S$ values are near to 1 , which indicates the excellent goodness of fit and confirms the refinements are accurate.
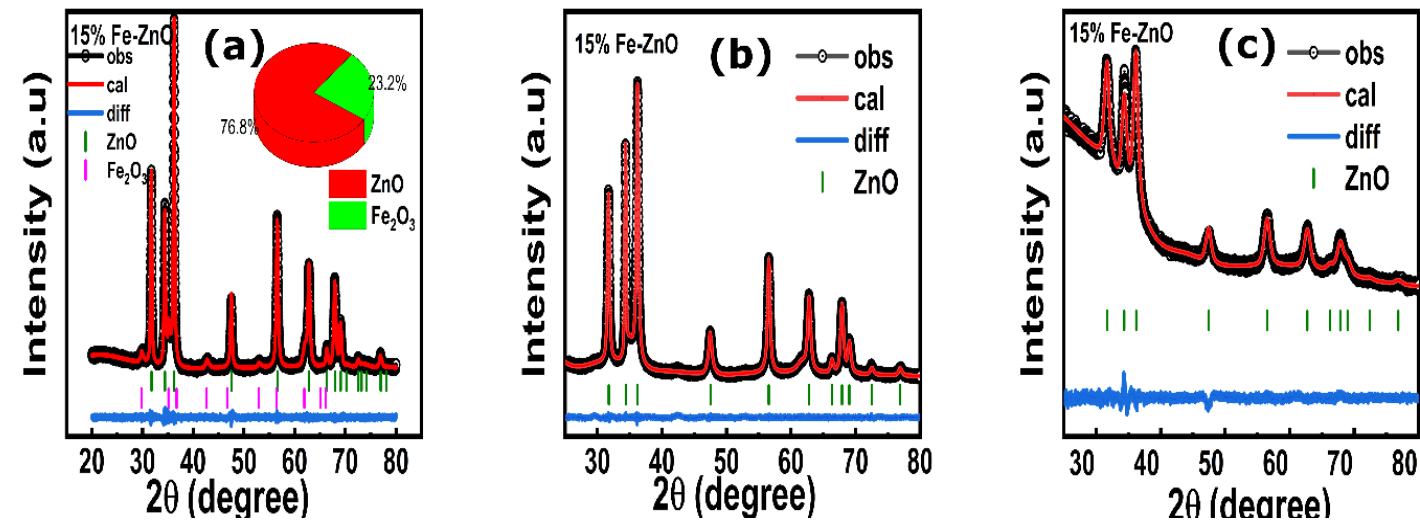

Figure 4 Observed and calculated XRD patterns of 15\% Fe-ZnO by (a) precipitation method (b) microwave method A and (c) microwave method B. The inset of figure (a) shows the pie chart representing the quantity of phase in samples obtained from the Rietveld analysis.

Table 1 Refine parameters from the Rietveld analysis of Fe-ZnO nanoparticles prepared by precipitation method.

\begin{tabular}{llllllllll}
\hline Fe concentration & $R_{w p}(\%)$ & $R_{p}(\%)$ & $R_{e}(\%)$ & $S(\%)$ & $\chi^{2}(\%)$ & $a(\AA)$ & $c(\AA)$ & $c / a$ & $\begin{array}{l}\text { Size (d) } \\
(n m)\end{array}$ \\
\hline $0 \%$ & 3.15 & 2.26 & 2.38 & 1.32 & 1.74 & 3.2493 & 5.2060 & 1.60219 & 40.90 \\
$5 \%$ & 2.51 & 1.91 & 2.04 & 1.23 & 1.51 & 3.2490 & 5.2048 & 1.60196 & 36.98 \\
$10 \%$ & 2.50 & 1.86 & 1.85 & 1.35 & 1.82 & 3.2499 & 5.2062 & 1.60195 & 32.10 \\
$15 \%$ & 1.98 & 1.55 & 1.86 & 1.06 & 1.13 & 3.2503 & 5.2065 & 1.60185 & 30.31 \\
\hline
\end{tabular}


Table 2 Refine parameters from the Rietveld analysis of Fe-ZnO nanoparticles prepared by Microwave method $A$.

\begin{tabular}{llllllllll}
\hline Fe concentration & $\mathrm{R}_{\mathrm{wp}}(\%)$ & $\mathrm{R}_{\mathrm{p}}(\%)$ & $\mathrm{R}_{\mathrm{e}}(\%)$ & $\mathrm{S}(\%)$ & $\chi^{2}(\%)$ & $\mathrm{a}(\AA)$ & $\mathrm{c}(\AA)$ & $\mathrm{c} / \mathrm{a}$ & $\begin{array}{l}\text { Size (d) } \\
(\mathrm{nm})\end{array}$ \\
\hline $0 \%$ & 1.86 & 1.38 & 1.32 & 1.41 & 1.99 & 3.2501 & 5.2093 & 1.60281 & 15.00 \\
$5 \%$ & 1.55 & 1.26 & 1.44 & 1.14 & 1.30 & 3.2503 & 5.2097 & 1.60283 & 15.40 \\
$10 \%$ & 1.90 & 1.45 & 1.44 & 1.31 & 1.72 & 3.2517 & 5.2124 & 1.60297 & 19.61 \\
$15 \%$ & 1.27 & 0.98 & 1.10 & 1.15 & 1.33 & 3.2518 & 5.2127 & 1.60301 & 21.83 \\
\hline
\end{tabular}

Table 3 Refine parameters from the Rietveld analysis of Fe-ZnO nanoparticles prepared by Microwave method $B$.

\begin{tabular}{llllllllll}
\hline Fe concentration & $\mathrm{R}_{w p}(\%)$ & $\mathrm{R}_{\mathrm{p}}(\%)$ & $\mathrm{R}_{\mathrm{e}}(\%)$ & $\mathrm{S}(\%)$ & $\chi^{2}(\%)$ & $\mathrm{a}(\AA)$ & $\mathrm{c}(\AA \AA)$ & $\mathrm{c} / \mathrm{a}$ & $\begin{array}{l}\text { Size (d) } \\
(\mathrm{nm})\end{array}$ \\
\hline $0 \%$ & 2.09 & 1.60 & 1.86 & 1.11 & 1.25 & 3.2634 & 5.2296 & 1.60250 & 8.20 \\
$5 \%$ & 2.31 & 1.68 & 1.67 & 1.38 & 1.91 & 3.2547 & 5.2152 & 1.60235 & 7.55 \\
$10 \%$ & 1.55 & 1.22 & 1.51 & 1.02 & 1.04 & 3.2499 & 5.2074 & 1.60232 & 7.02 \\
$15 \%$ & 1.92 & 1.41 & 1.67 & 1.15 & 1.32 & 3.2497 & 5.2072 & 1.60230 & 6.32 \\
\hline
\end{tabular}

Lattice parameters a and $\mathrm{c}$ along with the c/a ratio of nanoparticles prepared by precipitation method are displayed in Table 1. From the results presented in Table 1, it can be inferred that the c/a ratio is close to 1.6330 for the ideal close-packed hexagonal structure [41]. Lattice parameters a and $\mathrm{c}$ decreases by $5 \%$ and then increase by $10 \%$ and $15 \%$ Fe-ZnO nanoparticles compared to pure ZnO nanoparticles. Beltran et al. [42] also observed a similar decrease in lattice parameters a and c when iron concentration was increased up to $5 \%$ and showed a further increase in these parameters as the doping is increased beyond $5 \%$. The reason for this change in lattice parameters can be attributed to the difference in ionic radii of iron and zinc. In addition, the enhancement in the lattice parameter is dependent on synthesis conditions. Change in lattice parameters a and $c$ for the nanoparticles prepared from the microwave method is summarized in Table 2 and Table 3 . In the microwave assisted method $A$, lattice parameters a and $c$ increases with increasing iron concentration up to $15 \%$ keeping the c/a ratio in the range $1.6028-1.6030$.

However, lattice parameters decrease with increasing iron content up to $15 \%$ in the microwave method $B$ keeping the $c / a$ ratio in the range $1.6023-1.6025$. This change in lattice parameters in all samples is an indication of the dopant substitution, and the degree of change in lattice parameters depends on the method of synthesis. Our obtained c/a ratio in all samples is significantly smaller in comparison to an ideal stoichiometric wurtzite structure $(c / a=1.6330)$. This result may be an indication of the presence of oxygen and/or zinc vacancies in the ZnO lattice, which are formed to keep charge neutrality [43]. The presence of oxygen and zinc vacancies can be seen from the photoluminescence (PL) spectra of Fe-ZnO nanoparticles as shown in Figure 5 (a) and Figure 6 ( $a$ and c). 

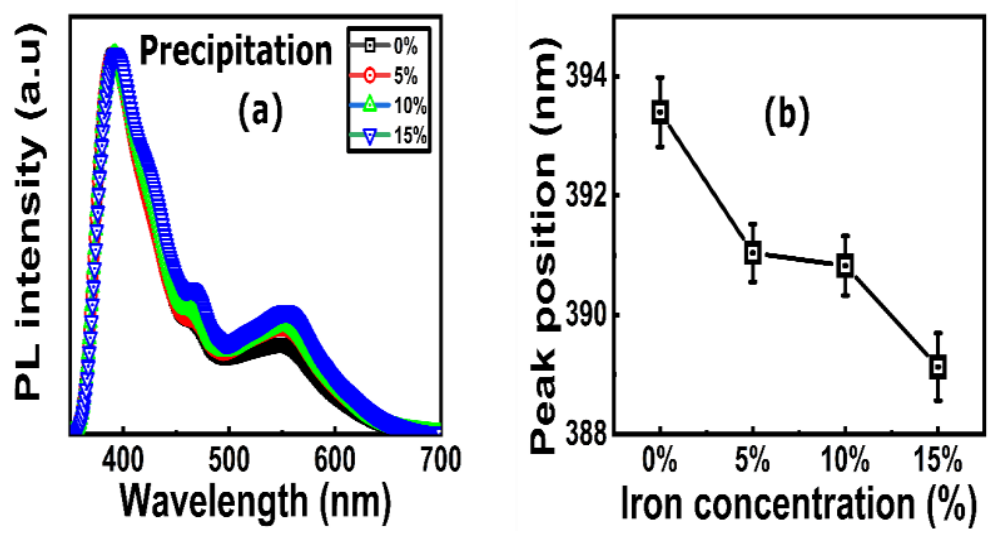

Figure 5 (a) Normalized PL spectra and (b) NBE peak position of Fe-ZnO nanoparticles prepared by precipitation method.
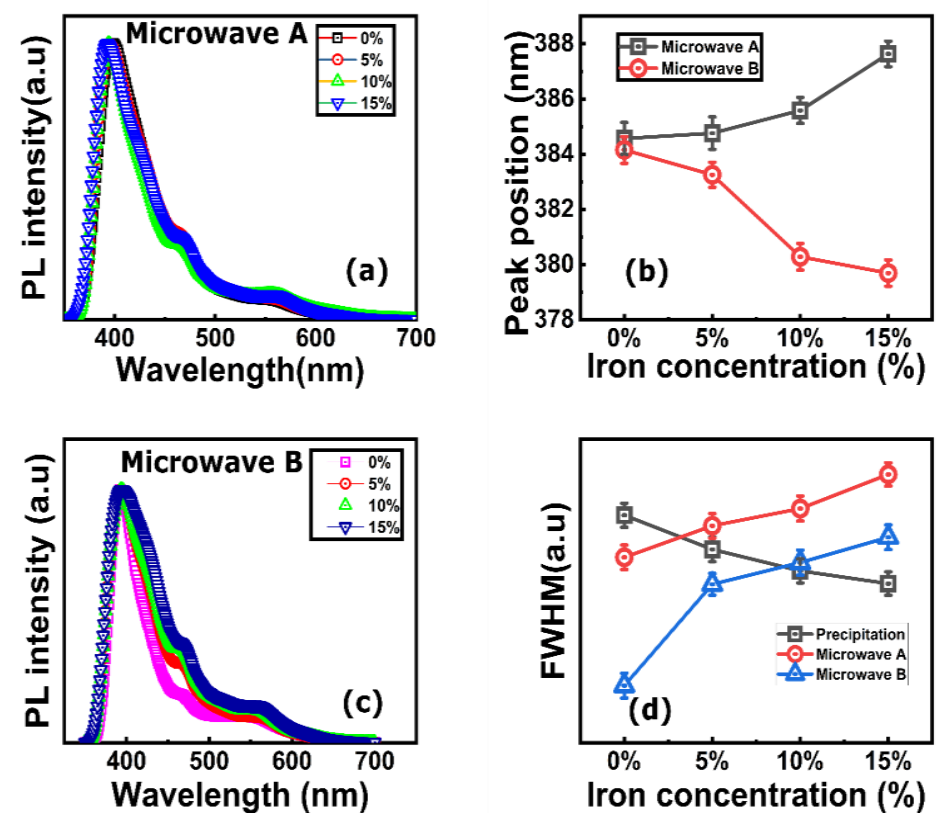

Figure 6 Normalized PL spectra of Fe-ZnO nanoparticles (a) microwave method A and (c) microwave method $B$, (b) NBE peak position of nanoparticles prepared by both microwave methods, and (d) FWHM of Fe-ZnO nanoparticles prepared by precipitation, microwave method $A$ and microwave method $B$.

It was also observed that the peak position (101) of Fe doped ZnO samples prepared by both precipitation method and microwave method $B$ shifted towards a lower diffraction angle when compared to the corresponding peak position in undoped $\mathrm{ZnO}$. This shift suggests a change in lattice parameters and cell volumes in the hexagonal structure of $\mathrm{ZnO}$, confirming that $\mathrm{Fe}^{3+}$ is replacing $\mathrm{Zn}^{2+}$ in the crystal structure of the $\mathrm{ZnO}$ matrix. As previously mentioned, peak shift may be attributed to the ionic radii difference of $\mathrm{Zn}^{2+}(0.74 \AA)$ comparing with that of $\mathrm{Fe}^{3+}(0.64 \AA)[20,44]$.

Crystallite size of nanoparticles prepared by both microwave method and precipitation method was also obtained from the Rietveld refinement analysis and is summarized in Table 1, Table 2, and Table 3. 
Microwave method $B$ does not show the presence of any secondary phases from the Rietveld analysis in heavily Fe doped ZnO nanoparticles. An increase in crystallite size was observed when the samples were prepared by microwave method A, as shown in Figure 3 (b). This difference in results may be because of different heat treatment process (convective heating in precipitation vs. rapid heating via microwave radiation) and different solvents (water in precipitation and microwave $A$ vs. ethanol in microwave $B$ method) that was used in precipitation method and microwave method. An increase in crystallite size in microwave method A may be due to a surface temperature that alters the molecular concentration to make tiny crystals grow at the surface, thereby increasing the molecular concentration at the crystal's surface which in turn increases the size [32]. These results are in good agreement with our direct images obtained from TEM.

\subsection{X-Ray Photoelectron Spectroscopy (XPS) Studies}

X-ray photoelectron spectroscopy (XPS) is used to analyze the chemical composition of elements present in the prepared samples. Detailed survey analysis was done for all the prepared samples. Figure 7 shows survey spectra for undoped and 15\% Fe-doped ZnO nanoparticles synthesized by microwave method $A$, microwave method $B$, and the precipitation method. From these figures, peaks related to zinc ( $\mathrm{Zn}$ ), iron (Fe), oxygen (O), and carbon (C) elements are observed. The inset of Figure 7 (a, b, c, \& d) shows Fe 2p core peaks of undoped and 15\% Fe-doped ZnO nanoparticles. For undoped nanoparticles, there are no peaks related to Fe whereas for all other samples peaks related to Fe are visible.
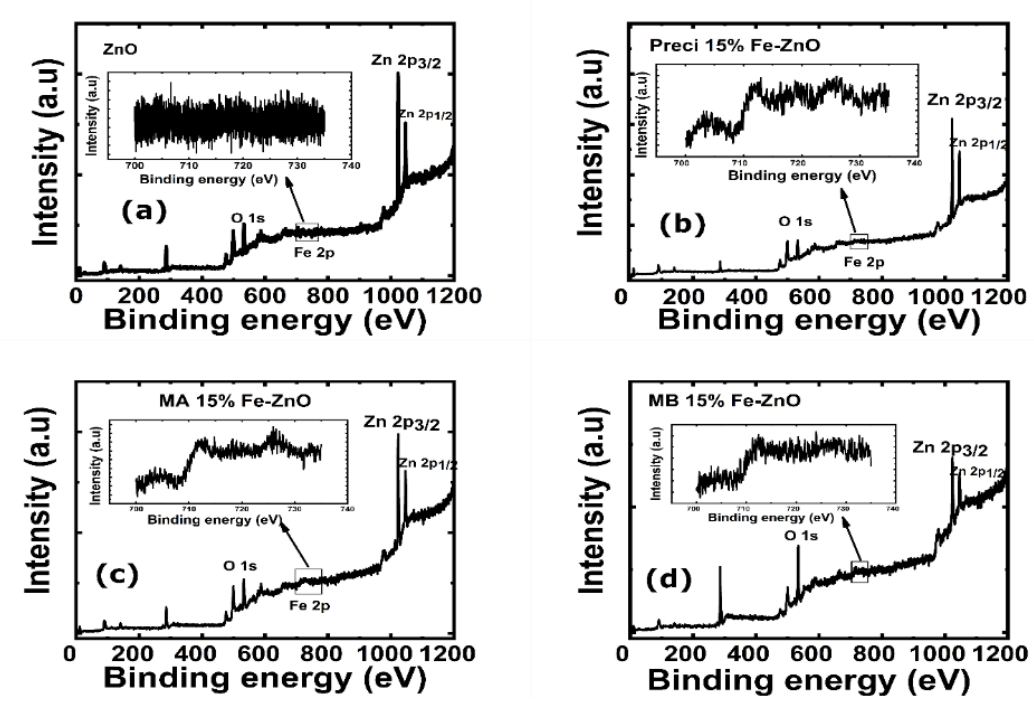

Figure 7 XPS spectra of (a) undoped $\mathrm{ZnO}$, (b, c, and d) 15\% Fe-ZnO synthesized by precipitation method, microwave method $A$ and microwave method $B$.

In order to verify the coexistence of the $\mathrm{Fe}^{2+}$ and $\mathrm{Fe}^{3+}$ ions in the Fe-doped $\mathrm{ZnO}$, we have deconvoluted the $15 \%$ Fe spectra as shown in figure 8 (c). As it can be observed Fe 2p3/2 and Fe 2p1/2 peaks as well as satellite peaks for precipitation method are identified. From figure, $\mathrm{Fe} 2 \mathrm{p}_{3 / 2}$ and Fe $2 \mathrm{p}_{1 / 2}$ peaks at $712.39 \mathrm{eV}$ and $726.16 \mathrm{eV}, 711.52 \mathrm{eV}$ and $725.35 \mathrm{eV}$, and $710.83 \mathrm{eV}$ and $724.56 \mathrm{eV}$ are observed for $15 \%$ Fe-doped nanoparticles with a peak separation of $13.7 \mathrm{eV}, 13.8 \mathrm{eV}$, and $13.7 \mathrm{eV}$ synthesized by microwave method A, microwave method $B$ and precipitation method respectively 
as shown in Figure 8(c). The differences in binding energy values result due to the spin-orbit coupling between Fe atoms. It is the interaction between the electron's spin and its orbital motion around the nucleus. When an electron moves in the electric field of the nucleus, the spin-orbit coupling causes a shift in the electron's atomic energy levels due to the electromagnetic interaction between the spin of the electron and the electric field. For Fe-Fe clusters in the samples, the difference in binding energy values of peaks would be around $13.10 \mathrm{eV}$, which is not in our case. Hence, it gives enough evidence that the Fe clusters are not present in our samples. These observed binding energy values were different from the binding energy values of elemental $\mathrm{Fe}$ and $\mathrm{Fe}$ in $\mathrm{FeO}$. This was also supported by our studies of the X-ray diffraction and Rietveld analysis. A satellite peak at $717.68 \mathrm{Ev}$ is observed, which is an indication of the Fe3+ states $[45,46]$. Additionally, the binding energy at $710.83 \mathrm{eV}$ for $2 \mathrm{p} 3 / 2$ represents $\mathrm{Fe}_{2} \mathrm{O}_{3}$ chemical state [47]. Hence, it confirms the presence of $\mathrm{Fe}_{2} \mathrm{O}_{3}$ phase in nanoparticles synthesized by precipitation method [48]. For the nanoparticles prepared by $\mathrm{MA}$ and $\mathrm{MB}$, the satellite peak is not clearly seen, and XRD data do no show Fe3+ states, therefore $\mathrm{Fe}_{2} \mathrm{O}_{3}$ formation can be ruled out for these samples.
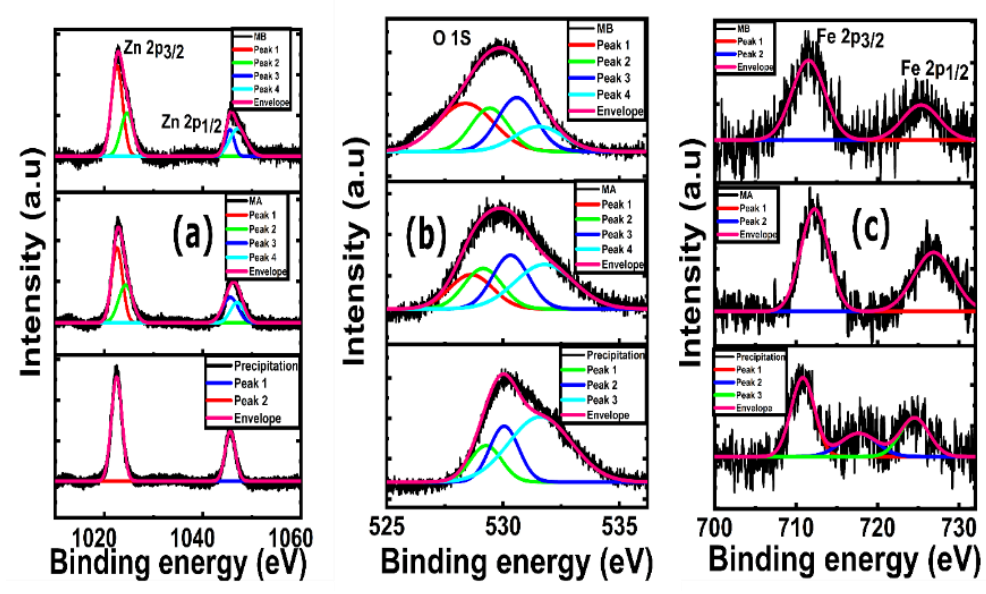

Figure 8 XPS spectrum of (a) Zn 2p peaks, (b) O1s peaks, and (c) Fe 2p peaks 15\% Fe-ZnO nanoparticles synthesized by Microwave method $A$, Microwave method $B$, and Precipitation method.

The binding energies of $\mathrm{Zn} 2 \mathrm{p}$ peaks are observed and are shown in Figure 8 (a). The binding

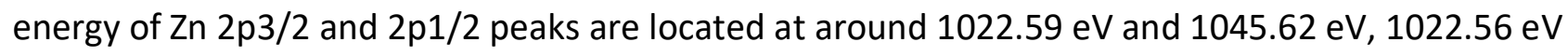
and $1045.53 \mathrm{eV}$, and $1022.50 \mathrm{eV}$ and $1045.59 \mathrm{eV}$ for 15\% Fe-doped ZnO prepared by MA, MB and precipitation method respectively. The observed binding energies of these peaks are different from the elemental binding energy values and close to the standard binding energy values of $\mathrm{Zn}$ in $\mathrm{ZnO}$. This indicates that zinc is present in 2+ chemical states in all samples [48]. In addition, $\mathrm{Zn} 2 \mathrm{p}$ peaks for nanoparticles synthesized by MA and MB were deconvoluted using Gaussian fitting. From the fitting, peaks other than at $1022 \mathrm{eV}$ and $1045 \mathrm{eV}$, peaks at $1024.30 \mathrm{eV}$ and $1024.60 \mathrm{eV}$ for $2 \mathrm{p} 3 / 2$ and $1047.62 \mathrm{eV}$ and $1047.19 \mathrm{eV}$ for $2 \mathrm{p} 1 / 2$ were also observed for MA and MB respectively. This can be attributed to the different chemical environments of the $\mathrm{Zn}^{2+}$ atom in the octahedral and tetrahedral sites of $\mathrm{ZnO}$ [49]. This might happen due to formation of excess amount of $\mathrm{Zn}$ species while synthesizing nanoparticles from microwave method. 
XPS core peak spectrum of $\mathrm{O}$ 1s for Fe-doped $\mathrm{ZnO}$ is shown in Figure 8 (b). The XPS spectrum of the $O 1$ s region present an asymmetric nature, indicating the presence of different oxygen species. All the peaks were deconvoluted using Gaussian fittings. Nanoparticles synthesized with MB method shows peaks at binding energies $528.39 \mathrm{eV}, 529.42 \mathrm{eV}, 530.59 \mathrm{eV}$, and $531.54 \mathrm{eV}$. Similarly, peaks are at binding energies $528.63 \mathrm{eV}, 529.14 \mathrm{eV}, 530.32 \mathrm{eV}, 531.78 \mathrm{eV}$ for nanoparticles synthesized by MA method and peaks are at binding energies $529.27 \mathrm{eV}, 530.05 \mathrm{eV}$, and $531.60 \mathrm{eV}$ for nanoparticles synthesized my precipitation method. The $\mathrm{O} 1 \mathrm{~s}$ peak observed at around and $530 \mathrm{eV}$, as shown in Figure 8 (b) is due to the $\mathrm{O}^{-2}$ bonding with the metal, in our case $\mathrm{Zn}$, i.e., $\mathrm{Zn}-\mathrm{O}$ [50]. The broad nature of the peak could be due to various coordinates of oxygen in the samples [51]. The peak on the lower binding energy centered around $529 \mathrm{eV}$ is ascribed to $\mathrm{O}_{2}{ }^{-}$ions surrounded by $\mathrm{Zn}^{2+}$ atoms of the wurtzite structure at tetrahedral sites [52]. The peak at higher binding energy centered around $531 \mathrm{eV}$ is ascribed to the oxygen vacancy defects $[53,54]$. In addition, binding energy at around $528 \mathrm{eV}$ prepared by MA and MB methods could be attributed to dissolved oxygen on the four fold hollow (FFH) sites of $\mathrm{ZnO}$. This suggest that weakly bound atomic oxygen may present in an octahedral site of $\mathrm{ZnO}$ [55].

Hence, the XPS result confirmed the presence of $\mathrm{Zn}$ and Fe $2 \mathrm{p}$ peaks along with $\mathrm{O}$ 1s in all Fe- $\mathrm{ZnO}$ nanoparticles synthesized by both precipitation and microwave method. $\mathrm{Zn}$ is in a $2+$ oxidation state and reduction of the intensity of $\mathrm{Zn}$ peak (not shown in figure here) with increasing doping concentration confirmed the substitution of $\mathrm{Fe}$ in $\mathrm{ZnO}$. Also the $\mathrm{Zn}$ atoms are in both tetrahedral and octahedral site of $\mathrm{ZnO}$ in nanoparticles synthesized by MA and MB method. Fe is in 3+ states in Fe-ZnO nanoparticles synthesized by precipitation method.

\subsection{Photoluminescence (PL) Studies}

Figure $5(\mathrm{a})$ and Figure $8(\mathrm{a}, \mathrm{c})$ shows PL spectra of Fe-doped ZnO nanoparticles prepared from both precipitation and microwave method. PL spectra were recorded for all samples at room temperature by using $325 \mathrm{~nm}$ as the excitation wavelength. From Figure 5 (a), it can be seen that there are three prominent peaks in the PL spectra of Fe-ZnO nanoparticles: a peak at around 395 $\mathrm{nm}$ and the other two peaks around $467 \mathrm{~nm}$ and $564 \mathrm{~nm}$. These peaks were related to the nearband-edge (NBE) peak of $\mathrm{ZnO}$, which is attributed to the radiative recombination of free excitions [56], and defect-related peaks (oxygen vacancies or $Z n$ interstitials) respectively [57]. For samples prepared by the precipitation method, the NBE emission peak showed a blue shift, from $393.4 \mathrm{~nm}$ to $389.1 \mathrm{~nm}$ and a decrease in full width at half maxima (FWHM) within the increase of iron doping $(5 \%, 10 \%$, and $15 \%)$ as shown in Figure 5 (b).

For samples prepared by microwave method B, the NBE emission peak also showed a blue shift, from $396.78 \mathrm{~nm}$ to $395.04 \mathrm{~nm}$, and an increase in FWHM with the increase of iron doping up to $15 \%$. This shift in the NBE peak for the samples prepared by both precipitation and microwave method $B$ may be due to strong exchange interaction between $d$ electrons of dopant ions and the $s$ and $p$ electrons of the host band [58].

On the other hand, for samples prepared with microwave method $A$, the NBE peak shifted towards a longer wavelength, resulting in a redshifted from $384.5 \mathrm{~nm}$ to $387.6 \mathrm{~nm}$ and an increase in the full width at half maxima (FWHM) with the increase in iron concentration as shown in Figure 6 (d). This increase in FWHM was also observed in cobalt-doped ZnO quantum dots and is attributed to the simultaneous effect of Coulomb interaction, quantum size effects, vacancies, and defects 
effects [3]. The shifts in NBE peaks in PL in the samples could be due to several effects present in quantum particles such as the creation of vacancies and defects, and variation in the size of nanoparticles during the growth process and doping.

\subsection{Absorption and Bandgap Measurements}

Absorption studies are summarized in Figure $9(a, b, c)$. Figures $9(a, b$, and c) show UV- visible absorption spectra of Fe-doped $\mathrm{ZnO}(0-15 \%)$ nanoparticles synthesized by both precipitation and microwave method. The optical absorption measurements were performed using a Cary-50 UVvisible spectrometer.
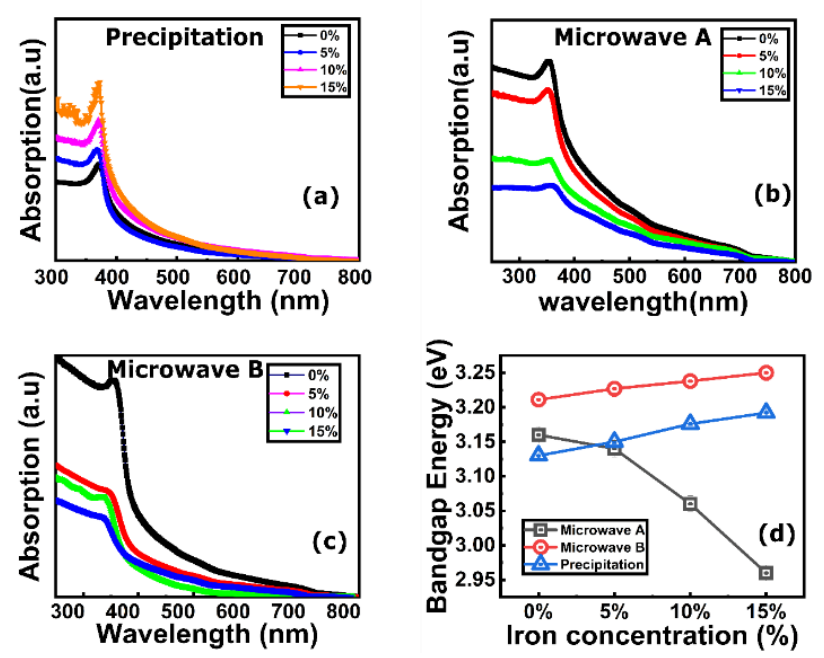

Figure 9 (a, b, c) Absorption spectra of Fe-ZnO nanoparticles and (d) bandgap variation of Fe-ZnO nanoparticles.

From Figure $9(a, b, c)$, it can be seen that there is a blue shift, nearly from $373 \mathrm{~nm}$ to $368 \mathrm{~nm}$ for the absorption edge with an increase in doping concentration in all samples prepared by the precipitation method. A shift from $356 \mathrm{~nm}$ to $349 \mathrm{~nm}$ in the absorption edge was also observed in the Fe-ZnO samples prepared by microwave method B. The blue shift in the NBE peak can be explained by the Moss-Burstein band filling effect [59]. Fe-doped ZnO nanoparticles are n-type semiconductors. The Fermi level in a doped semiconductor such as the one we studied will be inside of the conduction band since electrons occupy the state below the Fermi level in the conduction band. As a result, the absorption edge should shift to higher energy resulting in a blue shift. A similar result was also reported by Hammad et al. when Fe was doped (0\%-5\%) with ZnO. They observed a blue shift of the absorption edges from $354 \mathrm{~nm}$ to $335 \mathrm{~nm}$ in Fe-ZnO. This observed blue shift in $5 \%$ Fe-doped ZnO was also attributed to the Moss-Burstein band filling effect [60].

We observed a redshift, as shown in Figure 9 (c), nearly from $353 \mathrm{~nm}$ to $360 \mathrm{~nm}$, in the absorption peak with an increase in doping concentration in Fe-ZnO samples prepared by microwave method A. This redshift can be attributed to the $s p-d$ spin-exchange interactions between the band electrons and the localized d electrons of the transition metal ion substituting the cation [31]. Yousaf et al. [61] also observed a redshift in the absorption peak with increasing iron concentration. This observed trend in the absorption peak was also attributed to $\mathrm{sp}-\mathrm{d}$ spin-exchange interactions between localized d electrons of the dopant and the band electrons of $\mathrm{ZnO}$. 
The absorption spectra in Fe-ZnO were analyzed to extract the bandgap using the Tauc Plot equation (1) [62].

$$
(\alpha h v)^{2}=\mathrm{A}\left(\mathrm{h} v-E_{g}\right)
$$

where $A$ is the edge width parameter, $E_{g}$ is the bandgap energy, and $\alpha$ is the absorption coefficient. Figure 9 (d) shows the variation of bandgap energy with iron concentrations. From Figure 9 (d), it can be seen that the bandgap energy increases with an increase in iron content up to $15 \%$ in the nanoparticles prepared by the precipitation method and microwave method B. The bandgap energy increased from $3.13 \mathrm{eV}$ to $3.19 \mathrm{eV}$ and 3.21 to 3.25 respectively with the doping concentration. Wang et al. [63] also observed a similar result when doped with iron in ZnO. They observed an increase in bandgap from $2.90 \mathrm{eV}$ to $3.20 \mathrm{eV}$ when the iron concentration was increased up to $5 \%$. The $d$ - $d$ transition of Fe ions can explain this observed increase in bandgap energy. With microwave method A, bandgap energy decreased from $3.16 \mathrm{eV}$ to $2.96 \mathrm{eV}$. Srinivasulu [48] also reported that the optical band gap of ZnO nanoparticles decreased from $3.24 \mathrm{eV}$ to $3.01 \mathrm{eV}$ as the iron content increases up to $6 \%$.

The decrease in band gap was also observed in $\mathrm{Zn}_{1-\mathrm{x}} \mathrm{Fe} \times \mathrm{O}(\mathrm{x}=0,0.052,0.103,0.157$ and 0.212$)$ thin films [64]. For pure ZnO film, the bandgap energy was at $3.30 \mathrm{eV}$, and the bandgap decreased down to $2.80 \mathrm{eV}$ for $\mathrm{x}=0.212$, which was also explained due to $\mathrm{sp}$-d exchange interaction between band electrons and localized $d$ electrons of the transition metal ion.

\subsection{Fluorescent Lifetime Measurement}

The optical properties of iron-doped $\mathrm{ZnO}$ nanoparticles were further investigated by a fluorescent lifetime measurement. All the measurements were done at room temperature. Figure $10(a, b, c)$ shows the fluorescence decay of Fe-ZnO nanoparticles prepared by both precipitation and microwave method. From the figure, it can be seen that fluorescent lifetime decreases as iron concentration increases to $15 \%$ in both precipitation and microwave method $B$.
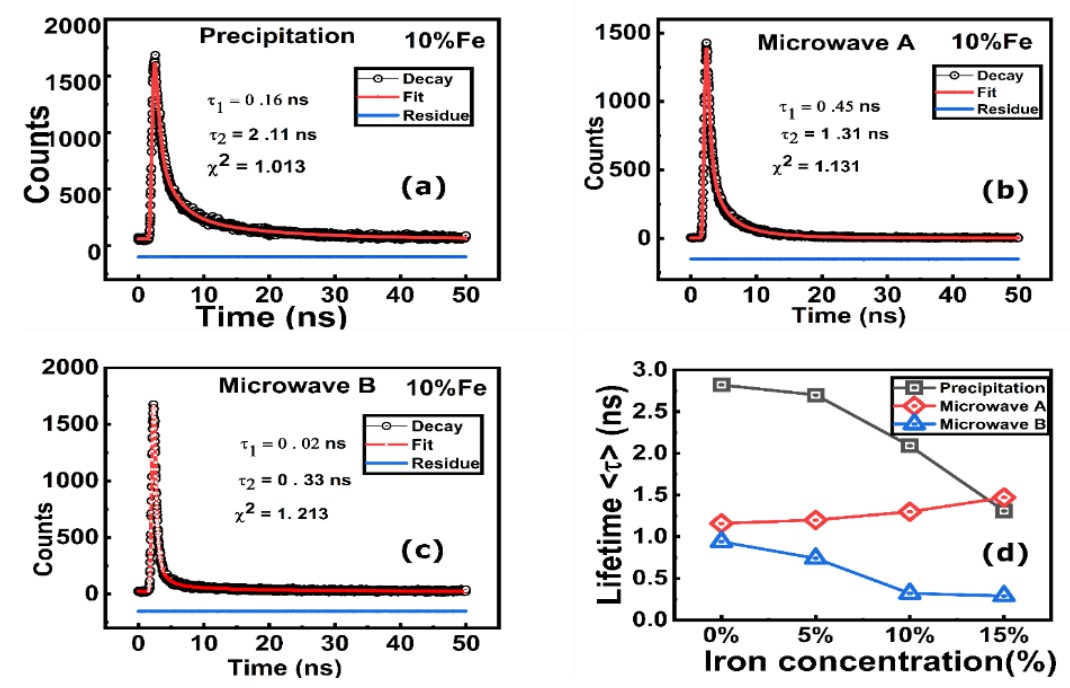

Figure 10 Lifetime measurement of $10 \%$ Fe-ZnO nanoparticles prepared by (a) precipitation method (b) microwave method $B(c)$ microwave method $A$ and $(d)$ variation of a lifetime with iron concentration. 
The equation (2) of Gaussian fitting for lifetime rates can be written as [65].

$$
F(t)=A+b_{1} \cdot \exp \left(-\frac{t}{\tau_{1}}\right)+b_{2} \cdot \exp \left(-\frac{t}{\tau_{2}}\right)
$$

where $b_{1}$ and $b_{2}$ are amplitudes and $\tau_{1}$ and $\tau_{2}$ and are the radiative decay times extracted from lifetime measurements. Table 4 summarizes the parameters extracted from the lifetime measurements.

Table 4 Lifetime parameters of Fe-ZnO nanoparticles prepared by precipitation and microwave methods.

\begin{tabular}{llllllllll}
\hline Iron concentration & \multicolumn{2}{l}{ Precipitation } & \multicolumn{3}{c}{ Microwave A } & \multicolumn{3}{c}{ Microwave B } \\
& $\tau_{1}(\mathrm{~ns})$ & $\tau_{2}(\mathrm{~ns})$ & $\chi^{2}$ & $\tau_{1}(\mathrm{~ns})$ & $\tau_{2}(\mathrm{~ns})$ & $\chi^{2}$ & $\tau_{1}(\mathrm{~ns})$ & $\tau_{2}(\mathrm{~ns})$ & $\chi^{2}$ \\
\hline $0 \%$ & 0.38 & 2.85 & 1.108 & 0.40 & 1.17 & 1.213 & 0.05 & 0.95 & 1.099 \\
$5 \%$ & 0.32 & 2.73 & 1.198 & 0.45 & 1.21 & 1.101 & 0.04 & 0.75 & 1.187 \\
$10 \%$ & 0.16 & 2.11 & 1.013 & 0.45 & 1.31 & 1.131 & 0.02 & 0.33 & 1.213 \\
$15 \%$ & 0.14 & 1.33 & 1.090 & 0.47 & 1.48 & 1.109 & 0.02 & 0.30 & 1.059 \\
\hline
\end{tabular}

From Figure 10 (d), the decrease in the lifetime of Fe-ZnO nanoparticles prepared by precipitation method and microwave method $B$ is shown. The decrease in a lifetime with an increase in iron content may be due to an increase in the nonradiative transition rate.

Li et al. also studied the lifetime measurement in $\ln _{2} \mathrm{~S}_{3}: \mathrm{Tb}^{3+}$ nanoshosphors and found a decrease in a lifetime with increasing $\mathrm{Tb}^{3+}$ content. They reported this shortening of a lifetime with increasing $\mathrm{Tb}^{3+}$ is also the nonradiative transition rate due to efficient energy transfer to luminescent killer sites which is related to some extent of concentration quenching [66]. This decrease in a lifetime with an increase in iron concentration can be attributed to the overall decrease in particle size in precipitation and the microwave method $B$. As the diameter of nanoparticles decreases, the ratio of area to volume increases. The resulting increase in surface area with particle size can also be related to enhancements in surface recombination. The decay time of surface recombination decreases with the decreasing diameter of the nanoparticle sample [67].

However, an increasing trend in the lifetime of Fe-ZnO nanoparticles prepared by microwave method $A$ was observed with an increase in iron content of up to $15 \%$. As discussed earlier, this may be due to a decrease in the nonradiative transition rate as iron content increases in the samples. $A$ similar result was also observed in a recent study up to certain doping percentage [68] and was explained due to defect concentrations. Another study reported a decrease in a lifetime in $\mathrm{Sm}^{2+}$ doped CdSe nano crystal [69]. The decrease in a lifetime with an increase in $\mathrm{Sm}^{2+}$ was attributed to the defect complexes resulting from the doping. In a high concentration of $\mathrm{Sm}^{2+}$ doping, a large number of $\mathrm{Sm}^{2+}$ existed in the crystal lattice of $\mathrm{CdSe}$ : Sm nanocrystals, which will introduce more $\mathrm{Sm}-\mathrm{Sm}$ ion pairs and increase the probability of non-radiative recombination.

Hence, it was observed that the fluorescent lifetime crucially depends on the size of nanoparticles and the preparation method. The smaller size of nanoparticles synthesized by 
microwave method $B$ resulted in a shorter luminescence lifetime suggesting the reduction in radiative recombination which is a desirable result in many nano-technological applications [70].

\subsection{Impedance Analysis}

The impedance spectroscopy provides an interconnection between the structural and transport properties in a nanomaterial. In Fe-doped ZnO nanoparticles, many defect states are arising due to changes in lattice parameters, an increase in oxygen vacancies, and grain boundaries due to doping. The creation of these defects significantly affects the transport properties of $\mathrm{ZnO}$ nanoparticles. We investigated transport properties in Fe-doped $\mathrm{ZnO}$ nanoparticles prepared by both precipitation and microwave methods by impedance analysis.

Nyquist plot technique is one of the important techniques for representing electronic properties such as the impedance of electrodes, grain boundary resistance, and grain boundary capacitance [71]. Figure 11 (a), (b) and (c) shows the impedance spectra of Fe-doped ZnO (0-15\%).
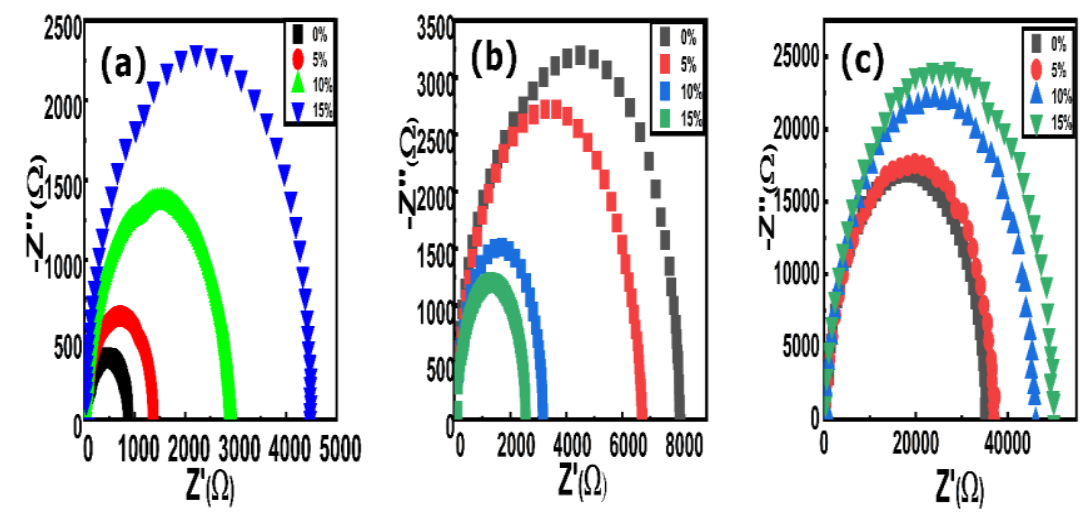

Figure 11 Nyquist plot of Fe-ZnO prepared by (a) precipitation method (b) microwave method $A$ and $(c)$ microwave method $B$.

Figure 11 shows the results of impedance spectroscopy plotted by the Nyquist plot. In a Nyquist plot, negative imaginary impedance $\left(-Z_{i m g}\right)$ is plotted against the real impedance $\left(Z_{\text {real }}\right)$. The real and imaginary parts of the impedance are related to the inverse of the conductance and capacitance respectively. Nyquist plots are analyzed by fitting them to an equivalent electrical circuit model. Here we have used the EIS (electrochemical impedance spectroscopy) spectrum analyzer to analyze our data. Based on the type of plots we can choose and/or construct different equivalent circuit models.

These circuit models are constructed with different parameters in series and/or in parallel combinations. The EIS analyzer is based on algorithms of the PDEIS (potentiodynamic electrochemical impedance spectroscopy) spectrometer. This program has been adapted to solve a wide range of tasks in impedance spectroscopy. In addition to data fitting to equivalent circuits with resistors, capacitors, inductors, constant phase, etc, the EIS spectrum analyzer provides various tests for data consistency and quality of fit. The data in Figure 11 was analyzed by an RC parallel equivalent circuit. It was observed that all the samples exhibit a single semicircle pattern in the Nyquist plot, suggesting the dominance of grain boundary resistance over the grain resistance [72]. As seen in Figure 11 (a) and (c), the diameter of the semicircle increases as the iron content increases 
and in Figure 11 (b) for the precipitation method, the diameter of the semicircle decreases as iron content increases for the microwave method. It has been reported in the literature that the resistivity of polycrystalline material in general increases with a reduction in grain size $[73,74]$.

In undoped $\mathrm{ZnO}$ nanoparticles prepared by the precipitation method and microwave method $\mathrm{B}$, the grain size is at a maximum in comparison with the relative grain size of doped nanoparticles. From the impedance analysis, it appears that the grain size decreases with increasing iron content in doped samples. On the other hand, the grain size is at a minimum in undoped $\mathrm{ZnO}$ prepared by microwave method $A$ and increases with increasing iron content. Table 4 summarizes the parameters extracted from the equivalent RC circuit model for the impedance analysis.

As shown in Table 5, electrical resistance increases and the effective capacitance decreases with increasing iron content in precipitation method and microwave method $B$. However, the resistance decreased and capacitance increased with increasing iron content in microwave method $A$. These results are consistent with the reduction and increment of grain size prepared from precipitation and microwave method ( $B$ and $A$ ) respectively. Since the capacitance is directly proportional to the diameter of a spherical capacitor, the capacitance of nanoparticles also decreases [3] in nanoparticles as the size decreases.

Table 5 Extraction of resistance and capacitance in Fe-ZnO nanoparticles.

\begin{tabular}{lllllll}
\hline $\begin{array}{l}\text { Fe } \\
(\%)\end{array}$ & Precipitation method & \multicolumn{2}{l}{ Microwave method $(\mathrm{A})$} & \multicolumn{2}{l}{ Microwave method $(\mathrm{B})$} \\
\hline & Capacitance(F) & $\begin{array}{l}\text { Resistance } \\
(\Omega)\end{array}$ & Capacitance(F) & $\begin{array}{l}\text { Resistance } \\
(\Omega)\end{array}$ & Capacitance(F) & Resistance $(\Omega)$ \\
0 & $5.44 \times 10^{-11}$ & 816 & $1.34 \times 10^{-11}$ & 7630 & $5.60 \times 10^{-13}$ & 33711 \\
5 & $4.99 \times 10^{-11}$ & 1308 & $3.12 \times 10^{-11}$ & 6330 & $3.18 \times 10^{-13}$ & 36137 \\
10 & $4.12 \times 10^{-11}$ & 2790 & $3.77 \times 10^{-11}$ & 3031 & $2.26 \times 10^{-13}$ & 44839 \\
15 & $2.05 \times 10^{-11}$ & 4469 & $4.61 \times 10^{-11}$ & 2410 & $2.06 \times 10^{-13}$ & 48797 \\
\hline
\end{tabular}

\section{Summary}

We have synthesized Fe-ZnO $(0 \%, 5 \%, 10 \%$, and $15 \%)$ nanoparticles by a precipitation method and a microwave-assisted method. It was demonstrated that the preparation of nanoparticles from the microwave method yielded a fast, relatively simple, and cost-effective technique compared to the precipitation method in synthesizing Fe-doped $\mathrm{ZnO}$ nanoparticles. The average size of Fe- $\mathrm{ZnO}$ nanoparticles prepared from the precipitation method ranged from 55-87 $\mathrm{nm}$ while the average particle size of the microwave-assisted method using water as a solvent (method $A$ ) ranged from 51-74 $\mathrm{nm}$. We also demonstrated that it is possible to obtain Fe-ZnO nanoparticles of size up to 11 $\mathrm{nm}$ with the help of PVP and ethanol using a microwave-assisted deposition method in 2 minutes. XRD analysis confirms the single-phase wurtzite structure in all samples prepared from both precipitation and microwave method except for $10 \%$ and $15 \%$ Fe-doped ZnO nanoparticles prepared from the precipitation method. XPS analysis confirms the incorporation of iron in $\mathrm{ZnO}$ and supports the formation of secondary phase $\mathrm{Fe}_{2} \mathrm{O}_{3}$ in $10 \%$ and $15 \%$ Fe-doped $\mathrm{ZnO}$ nanoparticles synthesized by precipitation method. The observed bandgap energy increased from $3.13 \mathrm{eV}$ to $3.19 \mathrm{eV}$ and 3.22 $\mathrm{eV}$ to $3.24 \mathrm{eV}$ respectively in samples prepared by the precipitation method and microwave method 
$B$ while the band gap energy decreased from $3.16 \mathrm{eV}$ to $2.96 \mathrm{eV}$ when prepared by a microwave method A using water as a solvent. Size dependence of the fluorescent lifetime of Fe-ZnO nanoparticles was established from the fluorescence lifetime measurements. An increasing trend in the fluorescent lifetime of Fe-ZnO nanoparticles prepared by microwave method $\mathrm{A}$ was observed with an increase in iron content of up to $15 \%$. In the Fe-ZnO samples prepared by precipitation method and microwave method $B$, the fluorescent lifetime decreased due to enhancement surface area. The dominance of grain boundary resistance over grain resistance was confirmed from the impedance spectrum using a Nyquist plot analysis. By utilizing two different solvents to prepare nanoparticles using precipitation and microwave-assisted deposition method of Fe-doped ZnO, we were able to tune the structural, optical, and electrical properties of Fe-ZnO nanoparticles. Based on the presented results in this work we can choose an effective way to synthesize Fe-ZnO nanoparticles which have a great potential for photovoltaic and optoelectronic applications.

\section{Acknowledgments}

The authors would like to acknowledge Rick Portman for TEM and also would like to acknowledge Dr. Alexei Grigoriev for assisting XRD measurement.

\section{Author Contributions}

G. Neupane organized the structure of the paper and contributed experimental data and preparation of the mansuscript. A. Kaphle gave suggestions and guidance on impedance spectroscopy. D. Mcllroy contributed to the XPS analysis. E. Echeverria gave suggestions and contributed in analyzing XPS measurements. P. Sankaran also contributed in XPS measurements. P. Hari supervised the work, prepared and revised the paper. All authors discussed the mansuscript and contributed to the final paper.

\section{Funding}

The authors would like to thanks OK -NASA EPSCoR (14-2-1205324) for financial support.

\section{Competing Interests}

The authors have declared that no competing interests exist.

\section{References}

1. Salahuddin NA, El-Kemary M, Ibrahim EM. Synthesis and characterization of ZnO nanoparticles via precipitation method: Effect of annealing temperature on particle size. Nanosci Nanotechnol. 2015; 5: 82-88.

2. Garcia MA, Merino JM, Fernández Pinel E, Quesada A, de la Venta J, Ruíz González ML, et al. Magnetic properties of ZnO nanoparticles. Nano Lett. 2007; 7: 1489-1494.

3. Tiwari RC, Hari P. Structural, optical and electrical properties of cobalt doped ZnO quantum dots. Funct Nanostructures. 2016; 1: 60-66.

4. Hasnidawani JN, Azlina HN, Norita H, Bonnia NN, Ratim S, Ali ES. Synthesis of ZnO nanostructures using Sol-Gel method. Procedia Chem. 2016; 19: 211-216. 
5. Guan YF, Pedraza AJ. Synthesis and alignment of $\mathrm{Zn}$ and $\mathrm{ZnO}$ nanoparticles by laser-assisted chemical vapor deposition. Nanotechnology. 2008; 19: 045609.

6. Rai P, Kwak WK, Yu YT. Solvothermal synthesis of ZnO nanostructures and their morphologydependent gas-sensing properties. ACS Appl Mater Interfaces. 2013; 5: 3026-3032.

7. Baruwati B, Kumar DK, Manorama SV. Hydrothermal synthesis of highly crystalline ZnO nanoparticles: A competitive sensor for LPG and EtOH. Sens Actuators B Chem. 2006; 119: 676682.

8. Bilecka I, Elser P, Niederberger $M$. Kinetic and thermodynamic aspects in the microwaveassisted synthesis of ZnO nanoparticles in benzyl alcohol. ACS Nano. 2009; 3: 467-477.

9. Khan I, Saeed K, Khan I. Nanoparticles: Properties, applications and toxicities. Arab J Chem. 2019; 12: 908-931.

10. Subban CV, Zhou Q, Hu A, Moylan TE, Wagner FT, Disalvo FJ. Sol-gel synthesis, electrochemical characterization, and stability testing of $\mathrm{Ti}_{0.7} \mathrm{~W}_{0.3} \mathrm{O}_{2}$ nanoparticles for catalyst support applications in proton-exchange membrane fuel cells. J Am Chem Soc. 2010; 132: 17531-17536.

11. Sharma P, Brown S, Walter G, Santra S, Moudgil B. Nanoparticles for bioimaging. Adv Colloid Interface Sci. 2006; 123-126: 471-485.

12. Haley B, Frenkel E. Nanoparticles for drug delivery in cancer treatment. Urol Oncol Semin Orig Investig. 2008; 26: 57-64.

13. Wang J, Polleux J, Lim J, Dunn B. Pseudocapacitive contributions to electrochemical energy storage in $\mathrm{TiO}_{2}$ (anatase) nanoparticles. J Phys Chem C. 2007; 111: 14925-14931.

14. Liu WT. Nanoparticles and their biological and environmental applications. J Biosci Bioeng. 2006; 102: 1-7.

15. Pearton SJ, Norton DP, Heo YW, Tien LC, Ivill MP, Li Y, et al. ZnO spintronics and nanowire devices. J Electron Mater. 2006; 35: 862-868.

16. Omri K, Bettaibi A, Khirouni K, El Mir L. The optoelectronic properties and role of $\mathrm{Cu}$ concentration on the structural and electrical properties of $\mathrm{Cu}$ doped $\mathrm{ZnO}$ nanoparticles. Physica B Condens Matter. 2018; 537: 167-175.

17. Jun JH, Seong H, Cho K, Moon BM, Kim S. Ultraviolet photodetectors based on ZnO nanoparticles. Ceram Int. 2009; 35: 2797-2801.

18. Singh P, Sinha OP, Srivastava R, Srivastava AK, Thomas SV, Sood KN, et al. Surface modified ZnO nanoparticles: Structure, photophysics, and its optoelectronic application. J Nanopart Res. 2013; 15: 1758.

19. Mohapatra J, Mishra DK, Mishra D, Perumal A, Medicherla VR, Phase DM, et al. Room temperature ferromagnetism in Co doped $\mathrm{ZnO}$ within an optimal doping level of $5 \%$. Mater Res Bull. 2012; 47: 1417-1422.

20. Wu XJ, Wei ZQ, Zhang LL, Wang X, Yang H, Jiang JL. Optical and magnetic properties of Fe doped ZnO nanoparticles obtained by hydrothermal synthesis. J Nanomater. 2014; 2014: 1-6.

21. Gu H, Jiang YZ, Yan M. Defect-induced room temperature ferromagnetism in Fe and Na Codoped ZnO nanoparticles. J Alloys Compd. 2012; 521: 90-94.

22. Sha WE, Ren $X$, Chen $L$, Choy WC. The efficiency limit of $\mathrm{CH}_{3} \mathrm{NH}_{3} \mathrm{Pbl}_{3}$ perovskite solar cells. Appl Phys Lett. 2015; 106: 221104.

23. Asanithi P, Chaiyakun S, Limsuwan P. Growth of silver nanoparticles by DC magnetron sputtering. J Nanomater. 2012; 2012: 1-8.

24. Manawi Y, Ihsanullah, Samara A, Al-Ansari T, Atieh M. A review of carbon nanomaterials' 
synthesis via the chemical vapor deposition (CVD) method. Materials. 2018; 11: 822.

25. Rahman IA, Padavettan V. Synthesis of silica nanoparticles by sol-gel: Size-dependent properties, surface modification, and applications in silica-polymer nanocomposites - a review. J Nanomater. 2012; 2012: 1-15.

26. Singh P, Kumar R, Singh RK. Progress on transition metal-doped ZnO nanoparticles and its application. Ind Eng Chem Res. 2019; 58: 17130-17163.

27. Hossienzadeh K, Maleki A, Daraei H, Safari M, Pawar R, Lee SM. Sonocatalytic and photocatalytic efficiency of transition metal-doped $\mathrm{ZnO}$ nanoparticles in the removal of organic dyes from aquatic environments. Korean J Chem Eng. 2019; 36: 1360-1370.

28. Aiswarya Devi S, Harshiny M, Udaykumar S, Gopinath P, Matheswaran M. Strategy of metal iron doping and green-mediated ZnO nanoparticles: Dissolubility, antibacterial and cytotoxic traits. Toxicol Res. 2017; 6: 854-865.

29. Limaye MV, Singh SB, Das R, Poddar P, Kulkarni SK. Room temperature ferromagnetism in undoped and Fe doped ZnO nanorods: Microwave-assisted synthesis. J Solid State Chem. 2011; 184: 391-400.

30. Glaspell G, Dutta P, Manivannan A. A room-temperature and microwave synthesis of M-doped $\mathrm{ZnO}$ (M = Co, Cr, Fe, Mn \& Ni). J Clust Sci. 2005; 16: 523-536.

31. Yu XH, Meng DW, Liu CZ, Xu K, Chen JF, Lu C, et al. Enhanced photocatalytic activity of Fe-doped ZnO nanoparticles synthesized via a two-step sol-gel method. J Mater Sci Mater Electron. 2014; 25: 3920-3923.

32. Manikandan A, Kennedy $\amalg$, Bououdina M, Vijaya JJ. Synthesis, optical and magnetic properties of pure and Co-doped $\mathrm{ZnFe}_{2} \mathrm{O}_{4}$ nanoparticles by microwave combustion method. J Magn Magn Mater. 2014; 349: 249-258.

33. Singh AK. Microwave synthesis, optical, structural and magnetic characterization of $\mathrm{ZnO} / \mathrm{Mn}$ doped ZnO nanoparticles. J Optoelectron Adv Mater. 2010; 12: 2255-2260.

34. Mohammadi E, Aliofkhazraei M, Hasanpoor M, Chipara M. Hierarchical and complex ZnO nanostructures by microwave-assisted synthesis: Morphologies, growth mechanism and classification. Crit Rev Solid State Mater Sci. 2018; 43: 475-541.

35. Fabbiyola S, Kennedy LJ, Ratnaji T, Vijaya JJ, Aruldoss U, Bououdina M. Effect of Fe-doping on the structural, optical and magnetic properties of $\mathrm{ZnO}$ nanostructures synthesised by Coprecipitation method. Ceram Int. 2016; 42: 1588-1596.

36. Ashkarran AA, Iraji zad A, Mahdavi SM, Ahadian MM. ZnO nanoparticles prepared by electrical arc discharge method in water. Mater Chem Phys. 2009; 118: 6-8.

37. Kombaiah K, Vijaya JJ, Kennedy LJ, Bououdina M. Studies on the microwave assisted and conventional combustion synthesis of hibiscus rosa-sinensis plant extract based $\mathrm{ZnFe}_{2} \mathrm{O}_{4}$ nanoparticles and their optical and magnetic properties. Ceram Int. 2016; 42: 2741-2749.

38. Adinaveen T, Vijaya JJ, Kennedy LJ. Studies on the structural, morphological, optical, and magnetic properties of $\alpha-\mathrm{Fe}_{2} \mathrm{O}_{3}$ nanostructures by a simple one-step low temperature reflux condensing method. J Supercond Nov Magn. 2014; 27: 1721-1727.

39. Basith NM, Vijaya JJ, Kennedy LJ, Bououdina M, Jenefar S, Kaviyarasan V. Co-doped ZnO nanoparticles: Structural, morphological, optical, magnetic and antibacterial studies. J Mater Sci Technol. 2014; 30: 1108-1117.

40. Moussa D, Bakeer DE, Awad R, Abdel-Gaber AM. Physical properties of ZnO nanoparticles doped with Mn and Fe. J Phys Conf Ser. 2017; 869: 012021. 
41. Wojnarowicz J, Omelchenko M, Szczytko J, Chudoba T, Gierlotka S, Majhofer A, et al. Structural and magnetic properties of $\mathrm{Co}-\mathrm{Mn}$ codoped $\mathrm{ZnO}$ nanoparticles obtained by microwave solvothermal synthesis. Crystals. 2018; 8: 410.

42. Beltrán JJ, Barrero CA, Punnoose A. Understanding the role of iron in the magnetism of Fe doped ZnO nanoparticles. Phys Chem Chem Phys. 2015; 17: 15284-15296.

43. Grotel J, Pikula T, Siedliska K, Ruchomski L, Panek R, Wiertel M, et al. Structure and hyperfine interactions of Fe-doped ZnO powder prepared by Co-precipitation method. Acta Phys Pol A. 2018; 134: 1048-1052.

44. Shayesteh SF, Dizgah AA. Effect of doping and annealing on the physical properties of $\mathrm{ZnO}: \mathrm{Mg}$ nanoparticles. Pramana. 2013; 81: 319-330.

45. Fanlo I, Gervilla F, Mateo E, Irusta S. X-ray photoelectron spectroscopy characterization of natural chromite from mercedita mine (Eastern Cuba): Quantification of the Fe3+/Fe2+ ratio. Eur J Mineral. 2008; 20: 125-129.

46. Karamat S, Rawat RS, Lee P, Tan TL, Ramanujan RV. Structural, elemental, optical and magnetic study of Fe doped ZnO and impurity phase formation. Prog Nat Sci Mater Int. 2014; 24: 142149.

47. Momose Y, Sakurai T, Nakayama K. Thermal analysis of photoelectron emission (PE) and X-ray photoelectron spectroscopy (XPS) data for iron surfaces scratched in air, water, and liquid organics. Appl Sci. 2020; 10: 1-29.

48. Srinivasulu T, Saritha K, Reddy KT. Synthesis and characterization of Fe-doped ZnO thin films deposited by chemical spray pyrolysis. Mod Electron Mater. 2017; 3: 76-85.

49. Ruiz CV, Becerra ME, Giraldo O. Structural, thermal, and release properties of hybrid materials based on layered zinc hydroxide and caffeic acid. Nanomaterials. 2020; 10: 163.

50. Claros M, Setka M, Jimenez YP, Vallejos S. AACVD synthesis and characterization of iron and copper oxides modified ZnO structured films. Nanomaterials. 2020; 10: 471.

51. Pan F, Guo Y, Cheng FF, Fa T, Yao SD. Synthesis of $\mathrm{ZnFe}_{2} \mathrm{O}_{4}$ nanomagnets by Fe-ion implantation into ZnO and post-annealing. Chinese Phys B. 2011; 20: 1-6.

52. Neena D, Kondamareddy KK, Bin H, Lu D, Kumar P, Dwivedi RK, et al. Enhanced visible light photodegradation activity of $\mathrm{RhB} / \mathrm{MB}$ from aqueous solution using nanosized novel Fe-Cd Comodified ZnO. Sci Rep. 2018; 8: 1-12.

53. Chang FM, Brahma S, Huang JH, Wu ZZ, Lo KY. Strong correlation between optical properties and mechanism in deficiency of normalized self-assembly ZnO nanorods. Sci Rep. 2019; 9: 1-9.

54. Zhao MJ, Sun ZT, Zhang ZX, Geng XP, Wu WY, Lien SY, et al. Suppression of oxygen vacancy defects in SALD-ZnO films annealed in different conditions. Materials. 2020; 13: 3910.

55. Jones TE, Rocha TC, Knop-Gericke A, Stampfl C, Schlögl R, Piccinin S. Thermodynamic and spectroscopic properties of oxygen on silver under an oxygen atmosphere. Phys Chem Chem Phys. 2015; 17: 9288-9312.

56. Neupane GR, Kaphle A, Hari P. Microwave-assisted Fe-doped ZnO nanoparticles for enhancement of silicon solar cell efficiency. Sol Energy Mater Sol Cells. 2019; 201: 110073.

57. Raj KP, Sadayandi K. Effect of temperature on structural, optical and photoluminescence studies on ZnO nanoparticles synthesized by the standard Co-precipitation method. Phys B Condens Matter. 2016; 487: 1-7.

58. Panigrahy B, Aslam M, Bahadur D. Aqueous synthesis of Mn- and Co-doped ZnO nanorods. J Phys Chem C. 2010; 114: 11758-11763. 
59. Suwanboon S, Tanattha R, Tanakorn R. Fabrication and properties of nanocrystalline zinc oxide thin film prepared by sol-gel method. Songklanakarin J Sci Technol. 2008; 30: 65-69.

60. Hammad TM, Griesing S, Wotocek M, Kuhn S, Hempelmann R, Hartmann U, et al. Optical and magnetic properties of Fe-doped $\mathrm{ZnO}$ nanoparticles prepared by the sol-gel method. Int J Nanopart. 2013; 6: 324-337.

61. Yousaf M, Rafique HM, Amin M, Ramay SM, Atiq S, Alzayed NS, et al. Visible-light-induced Fedoped $\mathrm{ZnO}$ magnetic photocatalyst nanoparticles for degradation of methylene blue. Dig J Nanomater Biostructures. 2017; 12: 91-98.

62. Tumuluri A, Naidu KL, Raju KJ. Band gap determination using Tauc 's plot for $\mathrm{LiNbO}_{3}$ thin films. Int J ChemTech Res. 2014; 6: 3353-3356.

63. Wang YS, Thomas PJ, O'Brien P. Optical properties of ZnO nanocrystals doped with Cd, Mg, Mn, and Fe ions. J Phys Chem B. 2006; 110: 21412-21415.

64. Chen ZC, Zhuge $\mathrm{L}, \mathrm{Wu} X \mathrm{XM}$, Meng YD. Initial study on the structure and optical properties of $\mathrm{Zn}_{1}$ xFe ${ }_{x} \mathrm{O}$ films. Thin Solid Films. 2007; 515: 5462-5465.

65. Haranath D, Sahai S, Joshi AG, Gupta BK, Shanker V. Investigation of confinement effects in ZnO quantum dots. Nanotechnology. 2009; 20: 425701.

66. Li ZF, Wang P, Yang TY, Yu H, Xiao BX, Zhang MZ. Enhanced luminescence with fast nanosecond lifetime in $\operatorname{In}_{2} \mathrm{~S}_{3}: \mathrm{Tb}^{3+}$ nanophosphors. J Phys Chem C. 2015; 119: 27688-27694.

67. Tang B, Zhang Q, Luo Q, Wu ZH, Qiu Y. Synthesis and optical properties of ZnO nanoneedles array. Asian J Chem. 2014; 26: 6292-6294.

68. Sun LW, Shi HQ, Li WN, Xiao HM, Fu SY, Cao XZ, et al. Lanthanum-doped ZnO quantum dots with greatly enhanced fluorescent quantum yield. J Mater Chem. 2012; 22: 8221-8227.

69. Yang JH, Gao JF, Yong SL, Ma XL, Liu LJ. Synthesis, characterization and optical studies on Sm² ${ }^{2+}$ doped CdSe nanocrystals: A blueshift and fixed emission with high quantum yields. Rare Metals. 2019; 38: 1097-1104.

70. Sönmez E, Meral K. Enhancement of photoluminescence lifetime of ZnO nanorods making use of thiourea. J Nanomater. 2012; 2012: 1-6.

71. Neupane GR, Hari P. Role of polyvinylpyrrolidone (PVP) on controlling the structural, optical, and electrical properties of vanadium pentoxide $\left(\mathrm{V}_{2} \mathrm{O}_{5}\right)$ nanoparticles. ChemistrySelect. 2020; 5: 11596-11607.

72. Irvine JT, Sinclair DC, West AR. Electroceramics: Characterization by impedance spectroscopy. Adv Mater. 1990; 2: 132-138.

73. Joshi DP, Sen K. Effect of grain size on the resistivity of polycrystalline material. Sol Cells. 1983; 9: 261-267.

74. Zeng H, Wu Y, Zhang JX, Kuang CJ, Yue M, Zhou SX. Grain size-dependent electrical resistivity of bulk nanocrystalline Gd metals. Prog Nat Sci. 2013; 23: 18-22. 
JEPT 2021; 3(3), doi:10.21926/jept.2103035

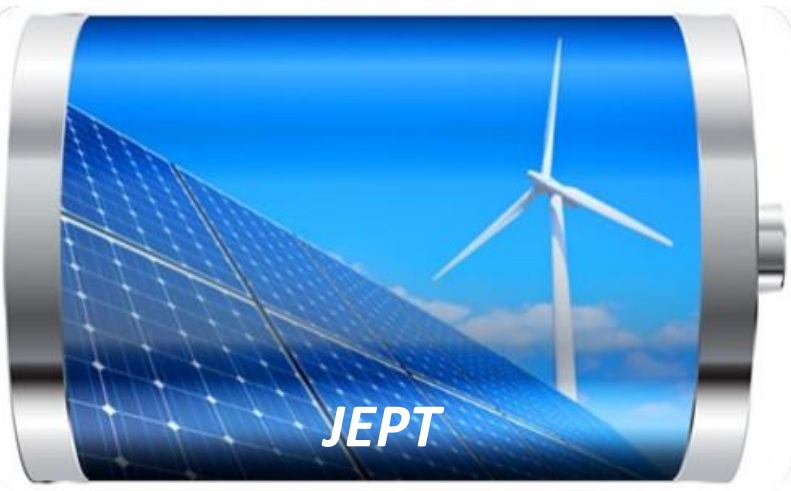

Enjoy JEPT by:

1. Submitting a manuscript

2. Joining in volunteer reviewer bank

3. Joining Editorial Board

4. Guest editing a special issue

For more details, please visit:

http://www.lidsen.com/journal/jept 